\title{
Proust contra a Degradação: gênese, infortúnios e redenção de um liuro
}

Luciana Persice Nogueira-Pretti ${ }^{1}$

A editora Âyiné lançou Proust contra a Degradação no Brasil, em 2018. Nessa narrativa entre a memória, o testemunho histórico e o ensaio, o escritor e artista plástico polonês Joseph Czapski discorre sobre Marcel Proust e sua obra, o que, em si, não é excepcional, e, à primeira vista, pode ser considerado como apenas mais um texto na imensa fortuna literária proustiana. Trata-se objetivamente da transcrição de uma série de doze conferências proferidas entre 1940 e 1941, ministradas como aulas de conversação em língua francesa, sobre o escritor francês e seu romance. Para quem conhece a trajetória da recepção da obra de Proust, a data revela uma anomalia de per se, pois, na França, em plena guerra, ou mesmo antes ou logo depois, do surrealismo ao existencialismo e sua rejeição da "literatura burguesa", via de regra, não se lia ou via com bons olhos a obra de Proust. ${ }^{2}$

Outro dado surpreendente sobre essas conferências é seu local de realização: um campo de trabalhos forçados na Sibéria. O próprio autor reconhece:

Eu pensava [...] com emoção em Proust, em seu quarto excessivamente aquecido, com paredes de cortiça, que ficaria bem espantado e, talvez, comovido em saber que vinte anos depois de sua morte, prisioneiros poloneses, depois de um dia inteiro passado na neve e no frio, que chegava frequentemente a quarenta graus [negativos], ouviam com interesse intenso a história da duquesa de Guermantes, da morte de Bergotte e tudo de que eu conseguia me lembrar desse mundo de descobertas psicológicas preciosas e de beleza literária. ${ }^{3}$

\footnotetext{
${ }^{1}$ Professora Adjunta da UERJ. Contato: luciana.persice@yahoo.com.br

${ }^{2}$ A hostilidade contra a obra e a figura de Proust é particularmente notória entre os surrealistas (ver, por exemplo, $O$ Manifesto Surrealista, de 1924 (BRETON, André, Manifestes du surréalisme. Paris: Gallimard, 1972, p.18) - a recusa da sociedade burguesa (retratada por Proust) e a filiação ao Partido Comunista sendo mandatórios no movimento. Para um apanhado sequencial e bastante completo da rejeição a Proust na França, entre os intelectuais e escritores, ver GUÉRIN 2004, onde são contemplados, entre outros, as várias invectivas de Louis Aragon (outro surrealista de monta), o ataque de Emmanuel Berl (ensaísta e historiador) em "La mort de la pensée bourgeoise" (na revista literária Europe, em janeiro de 1929, que faz um contraponto elogioso à obra engajada de André Malraux), assim como todo um florilégio de impropérios: o filósofo e jornalista Paul Nizan, ao falar do romance da sociedade burguesa decadente e esclerosada, menciona o ciúme de Swann (apud GUÉRIN 2004, p.172); uma enquete do Le Monde (1929) declara que "Proust é sem dúvida um escritor burguês, conformista contra-revolucionário” (p.173); e Sartre considera que Proust “'se escolheu burguês'. Seu 'espírito de análise' e sua 'psicologia intelectualista' fazem dele 'cúmplice da propaganda burguesa”, e ele não passa de "um clone de Paul Bourget” (p.175)... Os exemplos elencados por Guérin são muitos e, vistos em retrospectiva, espantosos. O crítico termina seu artigo lembrando a importância, para a recuperação e reencontro de Proust junto ao público leitor, de Roland Barthes e do seu Le Degré zéro de l'écriture (Seuil, 1953). As traduções livres aqui são nossas.

${ }^{3}$ CZAPSKI, J. Proust contra a Degradação. Belo Horizonte-Veneza: Âyiné, 2018, p.11-12.
} 
Pois Czapski não tinha consigo livros em seu gulag ermo e glacial, e dependia da memória para contar histórias sobre Proust, seu romance e seu mundo. Num evidente espelhismo de situações de confinamento, Czapski concebe e opera uma mise en abyme de projetos criativos à beira do desespero e do esgotamento físico (que, no caso de Proust, deviam-se à enfermidade); nessa solidariedade de projetos, no encontro virtual de condenados, ocorre a espantosa libertação, pela narrativa literária (escrita e/ou oral), de amarras (físicas ou não), que permite transpor limites e limitações, e, até, alcançar - como necessitavam esses prisioneiros de guerra - o esquecimento temporário, voluntário e proposital, nada proustiano, do quase insustentável fardo de sua condição.

Em sua introdução ao conjunto unificado das conferências, o autor explica que seu "ensaio é apenas um humilde tributo de reconhecimento à arte francesa" que o ajudou, e a seus companheiros, "a viver durante esses alguns anos na URSS": ${ }^{4}$ o polêmico romance (em seu tempo, antes de tornar-se um "clássico" da literatura contemporânea francesa) À la Recherche du Temps Perdu, Em Busca do Tempo Perdido, tão cheio de duques e duquesas (como dizem ter lamentado André Gide ao recusar-se a publicar o primeiro volume pela NRF), é, para o conferencista e seus ouvintes, um "mundo de descobertas psicológicas preciosas e de beleza literária”. 5 Em seu texto, Czapski revela que conhece a fundo a obra e a vida de Proust, e ressalta não apenas trechos do romance e algumas anedotas sobre a biografia do escritor, mas também elementos ensaísticos que embasam a ficção, em surpreendentes associações e revelações desse mundo proustiano impregnado de saber teórico e capacidade crítica; rememorar esse mundo é um exercício coletivo que o autor assim explica:

A alegria de poder participar de um esforço intelectual que nos dava prova de que ainda éramos capazes de pensar e reagir às coisas do espírito, sem nada em comum com nossa realidade de então, coloria de rosa essas horas passadas no grande refeitório [...] onde revivíamos um mundo que nos parecia, então, perdido para nós, para sempre [...] Nesse contexto lúgubre, essas horas passadas com lembranças de Proust, Delacroix, me parecem as mais felizes. ${ }^{6}$

Esse reviver de um mundo - decerto idealizado - "que lhes parecia perdido para sempre", essa nostalgia de tempos de paz e bem estar, de ambientes de arte e beleza, de convívio social e trocas intelectuais, de um mundo "civilizado" (em oposição à "barbárie" da guerra e suas atrocidades), é, sobretudo, um exercício de reconquista da própria humanidade, de retomada da própria identidade; reviver o mundo da Belle Époque francesa, nesse contexto, é reanimar o humanismo em sua essência, e preservar-se contra a degradação do indivíduo e da sociedade; reavivar o espírito dreyfusard desses tempos aparentemente perdidos (e Proust foi um dos primeiros a defenderem Dreyfus) é recuperar-se e redescobrir-se na rememoração de saberes e prazeres; este foi o feito assombroso dessas conferências no gulag de Griazowietz.

E o espelhismo entre o escritor polonês e o francês continua com as dificuldades enfrentadas por Czapski, como ocorrera com Proust, ao tentar publicar e divulgar seu trabalho na França - justo esse texto que, como anunciou em suas primeiras linhas, é um "tributo de reconhecimento à arte francesa".

\footnotetext{
${ }^{4}$ Ibidem, p.12.

${ }^{5}$ Ibidem, p.12.

${ }^{6}$ Ibidem, p.12.
} 
Veremos a seguir caminhos e descaminhos da trajetória dessa obra, de sua produção, edição e divulgação, entre a narração da história e a publicação de uma narrativa que possui traduções e versões, densidades, e facetas ainda a serem desveladas. Começando com os espelhismos entre Czapski e Proust, passando pelo esforço mal recompensado de publicar outros relatos e testemunhos do autor sobre a guerra, pela abordagem de alguns aspectos de sua tradução, o comentário da passagem da narração à narrativa, e terminando no enfoque de seus grafismos metaescriturais, pretendemos retraçar a história desse pequenino livro, cujos infortúnios, entre manuscritos extraviados e tapuscritos desdobrados revelam aspectos desconcertantes do pós-guerra na França. Nesse contexto, a pretendida homenagem à literatura francesa (pois Czapski não disserta apenas sobre Proust, mas sobre todo o seu tempo) é eclipsada por imperativos ideológicos, relegando esse belo texto a uma sobrevida extemporânea - como condiz a toda obra de arte.

Nesse sentido, e permeando a descrição dessa trajetória, subjaz aqui o entendimento de Proust contra a degradação como um "lugar de memória", tal como conceituado pelo historiador social Pierre Nora: Czapski faz de seu livro o suporte a um só tempo material e simbólico de uma "vontade de memória", 7 de uma necessidade pessoal e obstinada de preservar a lembrança da experiência de sua coletividade; livro, assim, vislumbrado, em seu projeto, como arquivo (termo caro a Nora), mas que se prova rastro movediço e instável, vestígio - literário e histórico - que quase se apagou por completo.

\section{1 - De um cosmopolitismo a outro, espelhismos entre Czapski e Proust}

Józef Marian Franciszek Hrabia Hutten-Czapski (1896-1993) nasceu em Praga (no então Império AustroHúngaro), em uma família da aristocracia polonesa. Segundo uma curta biografia publicada na página web do periódico polonês Kultura Paryska (que ele ajudou a fundar no imediato pós-guerra e no qual cooperou durante toda a sua vida no exílio, na França), ele aprendeu, além do polonês materno, francês, alemão e russo - como convinha numa educação polonesa aristocrática (Anônimo, s/d, s/p). Esse lugar-comum de sua biografia é relativizado pelo próprio Czapski em entrevista, ${ }^{8}$ que explica ter aprendido, com uma governanta alemã, alemão e música (seu primeiro pendor artístico) e algum francês, com uma governanta francesa; o russo, só veio a aprender em São Petersburgo, onde terminou o colégio e fez o primeiro ano de direito, até a eclosão da I Guerra Mundial - tornando-se fluente em russo e ávido leitor de Tolstói e Dostoievski.

Apesar dos parcos conhecimentos da língua francesa, entretém, antes da guerra, correspondência com o escritor francês Romain Rolland (1866-1944), sobre o pacifismo e outros “princípios dostoievskianos”. Com o início da Primeira Guerra, alista-se e participa do conflito com uma função fora de campo, e é encarregado de investigar o paradeiro de seus companheiros de armas poloneses capturados pelo exército russo; descobre que foram fuzilados. O choque dessa constatação antecipa o trágico desenlace dos acontecimentos que constituem

\footnotetext{
${ }^{7}$ NORA, P. "Entre história e memória: a problemática dos lugares”, Revista Projeto História, v.10, p.7-28, 1993, p.9. São lugares de memória: "Museus, arquivos, cemitérios e coleções, festas, aniversários, tratados, processo verbais, monumentos, santuários, associações, [...] marcos testemunhas de uma outra era”, p.13.

${ }^{8}$ Czapski. Témoin du siècle, $59 \mathrm{~min}, 2015$, de Andrzej Wolski, disponível em https://www.arte.tv/fr/videos/054728-000A/jozef-czapski-1896-1993/ (entre 27/03/2020 e 16/05/2020). Documentário que reúne vários trechos de entrevistas e depoimentos, ilustrado com fotografias de família e dos quadros do artista, além de cenas filmes e reportagens de época.
} 
o contexto do livro Proust contra a Degradação, durante a II Guerra Mundial. A biografia que consta na página web da Kultura acrescenta que esse pacifista ainda participará da "Guerra Polono-Bolchevique" (ou SovietoPolonesa, ou Russo-Polonesa, travada em decorrência da I Guerra Mundial, no intuito de demarcar fronteiras entre os dois países, 1919-1921; o termo bolchevique mostra a tendência anticomunista da revista e a longa luta ideológica que vai travar contra o regime soviético, inclusive em solo francês).

Depois da Grande Guerra, Czapski (cuja família perde a fortuna e as posses com a anexação da Polônia pela URSS) estuda Belas-Artes na Cracóvia, e, em 1923, integra, junto com uma dúzia de amigos e colegas estudantes, o grupo Komitet Paryski, ou K.P. - de onde o nome do movimento kapista. Czapski será responsável por esse Comitê de Paris, cidade que ainda é capital inconteste das artes; lá, ele vive seis anos e conhece artistas e intelectuais. Até o início da II Guerra Mundial, o pintor transita entre Paris, Varsóvia e Pittsburg (EUA) expondo quadros e escrevendo textos teóricos e críticos sobre arte e literatura.

Os kapistas contestam a arte acadêmica polonesa, inspiram-se, sobretudo, nos impressionistas e pósimpressionistas, e na ideia de "arte pura" (não política ou militante), e visam a aperfeiçoar os estudos em Paris. Para tal, arrecadam fundos realizando toda sorte de eventos (loterias, bailes, saraus literários...), que têm por consequência, além do fluxo de caixa, uma intensificação das relações entre uma nova geração de artistas poloneses e artistas franceses. Retoma-se, assim uma cooperação existente desde o século XIX, e que perdurara até o início da I Guerra Mundial. ${ }^{9}$ Nesse ambiente artístico, social e político, Czapski conhece pessoas que conviveram nos círculos multinacionais e cosmopolitas de Proust, como Daniel Halévy, François Mauriac, Jean Cocteau, e Misia Godebska-Sert (alguns dos quais serão mencionados mais adiante), logo em seguida à morte de Proust (1922).

Em 1924, Czapski lê "um dos volumes" da Recherche, "talvez O caminho de Guermantes", que considera uma

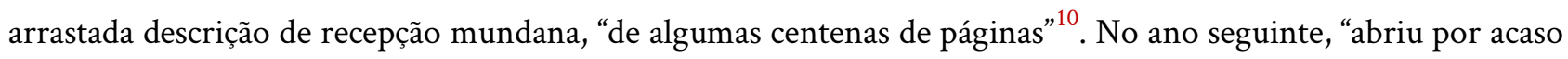
Albertina desaparecida" e, "de repente", leu "da primeira página à ultima", ${ }^{11}$ e deslumbrou-se com seus temas ("o desespero, a angústia do amante abandonado", "todas aquelas formas de ciúme retrospectivo"... ${ }^{12}$ Em 1926, convalescendo de tifo num hospital em Londres, lê, então, toda a Recherche e "descobre o novo aparelho de análise psicológica" e um "novo mundo de poesia" que constituem o "tesouro da forma literária" proustiana. ${ }^{13}$ Reconhecer esse tesouro é também começar a traçar afinidades com o universo de Proust, e as questões comuns aos dois escritores são várias: a enfermidade, a convalescência, o confinamento, o homossexualismo, o interesse pelas artes e seu mundo, e uma veia dreyfusarde, republicana não-comunista estão entre as principais.

Essencialmente, entre o escritor francês e seu leitor polonês, dois intelectuais de formação humanista, espelham-se uma visão e uma perspectiva cosmopolitas, que ultrapassam fronteiras entre culturas e línguas, assim como transpõem eventuais limites entre as artes - e não à toa a palavra "transposição" é recorrente ao

\footnotetext{
${ }^{9}$ O mais famoso evento foi um baile a fantasia patrocinado por Pablo Picasso, em 1925. Dentre os participantes do comitê, estão figuras já ilustres no cosmopolitismo da Belle Époque: Pierre Bonnard, Olga Boznańska, Constantin Brancusi, Jean Cocteau, Antoine Cierplikowski, Misia Godebska-Sert, Léopold Zborowski, entre outros, numa interação renovada entre aristocratas e artistas.

${ }^{10}$ CZAPSKI, J, op. cit, p.16.

${ }^{11}$ Ibidem, p.16-17.

${ }^{12}$ Ibidem, p.17.

${ }^{13}$ Ibidem, p.17.
} 
longo de Proust contra a degradação, revelando a clarividente compreensão de Czapski do trabalho consciente e proposital de transposição das artes que fundamenta a estética da Recherche. No espelhismo, Czapski transpõe o aprisionamento de Proust ao seu, o mundo de Proust ao seu, o tempo perdido de Marcel ao seu, e, na busca de lembrar-se da obra literária, encontra e recupera, como o narrador da Recherche, a vocação sublimadora da arte.

\section{2 - De um campo a outro e as agruras das publicações}

Com a eclosão da II Guerra Mundial, o pintor polonês vai para o fronte e é capturado pelos soviéticos, já em 1939. Inicialmente, vai para o campo de Starobielsk (onde havia 4 mil oficiais poloneses, entre outros detentos); adoece em 1940, é transferido para o campo de Griazowietz (onde haverá pouco mais de quatrocentos oficiais; nesse período, Czapski lembra que houve um total de 15 mil prisioneiros transferidos para campos de trabalho forçado na Sibéria ${ }^{14}$ ) - antigo convento ortodoxo em ruínas onde realiza suas conferências sobre Proust "entre os retratos de Marx, Engels e Lênin". ${ }^{15}$

A prática coletiva da realização de conferências (iniciada já no campo de Starobielsk) foi a maneira encontrada para tentar sobreviver mental e emocionalmente ao horror do cárcere, da deportação e do trabalho forçado no inverno siberiano. Verdadeiro "lugar da memória", essas conferências reúnem e agregam vários oficiais, que participam fazendo palestras sobre assuntos de seu conhecimento ou especialidade (como a história do livro, a história da Inglaterra, a história das migrações, a história da arquitetura, o alpinismo, a América do Sul... Czapski fez várias sobre pinturas francesa e polonesa, e literatura francesa. Essa listagem de temas é acompanhada dos nomes dos respectivos conferencistas, num registro histórico que tira do anonimato e do esquecimento, mesmo que de modo parcial e incompleto, pessoas empenhadas nessa impressionante empreitada coletiva. ${ }^{16}$ Operando como "arquivo" (conforme Nora), o livro de Czapski guarda a memória desses oficiais, sua resiliência e seus talentos.

Para as conferências sobre Proust, escreveu, em cadernos escolares, textos curtos e diagramas, que lhe servem de apoio à preparação da apresentação oral (na terminologia de Pierre Nora, arquivos materiais de uma rememoração simbólica). Plenos de cores e toda sorte de indicações gráficas, esses documentos híbridos entre texto e desenho, ensaio e arte, serão, anos mais tarde, reproduzidos junto com o texto publicado e, na maioria das reproduções da obra, figurarão como ilustração de capa (voltaremos a eles mais adiante).

\footnotetext{
${ }^{14}$ Ibidem, p.10.

${ }^{15}$ Ibidem, p.11.

${ }^{16}$ Ibidem, p.10-11.
} 


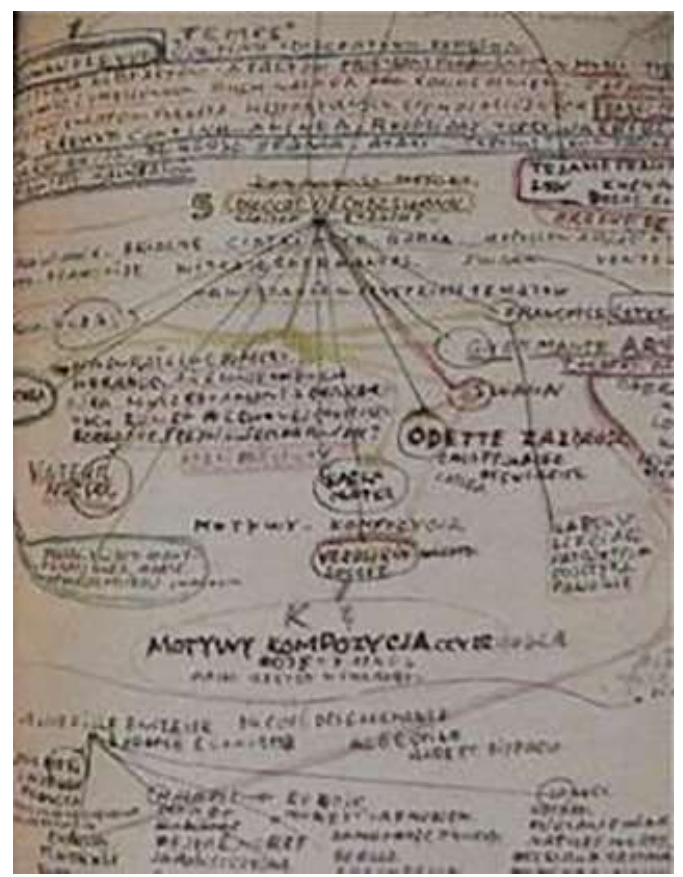

Imagem disponibilizada por http://www.ladilettantelle.com/article-proust-au-goulag-une-histoire-envoutante-

66509124.html, acesso em 18/12/2020

Com as mudanças no alinhamento da URSS durante o conflito (que inicialmente tem um pacto de não agressão com a Alemanha, mas que, "agredida", muda de "campo", e, portanto, ironicamente, torna-se aliada da Polônia), os oficiais poloneses são anistiados e reintegrados ao contingente de guerra, em 1941. Czapski segue para o Oriente Médio, e lhe é confiada uma missão semelhante à que tivera ao final da I Guerra Mundial: buscar seus antigos companheiros de armas. Descobre que seus infortúnios pessoais durante o conflito levaram-no, paradoxalmente, a fazer parte do grupo de pouco mais de 400 sobreviventes ao massacre de Katyn - destino da aterradora maioria dos prisioneiros de vários gulags, cujas estimativas do total de mortes variam entre 30 mil e 15 mil (não haverá números oficiais ou definitivos). O milagre de sua sobrevivência deveu-se ao fato de que a diplomacia nazista favorecera os poloneses originários de regiões anexadas pela Alemanha (fato que só se descobre na década de 1990, ${ }^{17}$ depois da Queda do Muro de Berlim). A narrativa detalhada dessa busca, dessa descoberta e desse massacre é objeto de dois títulos de Czapski: Souvenirs de Starobielsk (1944, em polonês, e 1945, em francês) e Terre inhumaine (1949, em polonês, e 1950 em francês); ela é apenas esboçada na introdução a Proust contra a Degradação.

Nessa introdução, datada de 1944 (e não 1987, quando da primeira publicação do livro; não haverá uma nota atualizada do autor por essa ocasião) Czapski explica que seu ensaio sobre Proust foi ditado em francês a dois companheiros de detenção ainda em Griazowietz, e os editores do ensaio, seja em francês ou em suas várias traduções ulteriores, ressaltam, como elemento atrativo à leitura, que se trata de uma "transcrição feita no calor do momento" (informação repetida na contracapa da edição brasileira). Essa questão será discutida mais adiante. Por ora, vale destacar que a primeira publicação de Proust contre la déchéance foi uma versão em polonês, nos

\footnotetext{
${ }^{17}$ MAINBERGER, S. e STEWART, N. (Dir.). À la recherche de la Recherche. Les notes de Joseph Czapski sur Proust au camp de Griazowietz, 1940-1941. Paris: Noir sur Blanc, 2016, p.19, n.2.
} 
números 12 (p.25-36) e 13 (p.22-43) da revista Kultura, em 1948, em Paris (vertido do francês por Teresa Skórzewska, ${ }^{18}$ sob o título "Proust em Griazowietz").

Esse ensaio, "tributo de reconhecimento à arte francesa", que deveria, por princípio, atrair o interesse dos editores franceses, só será publicado em língua francesa na Suíça, em 1987 (ou seja, quase quarenta anos depois da publicação de sua tradução para o polonês). O título Proust contre la déchéance, conférences au camp de Griazowietz é da Éditions Noir sur Blanc, que assim explica a recepção do copião: “Um primo de Czapski propôs o texto escrito em francês, ele estava cheio de erros, mas publicamos tal qual, para lhe conservar o charme original”. ${ }^{19}$ O livro não teve repercussão, apesar de uma aparição discreta, em 1988, na emissão televisiva cultural Apostrophes, de Bernard Pivot (que mostrou a capa do livro e comentou rapidamente sua publicação num programa dedicado a Proust) - signo máximo, na França, de relevo e atualidade em termos de produção editorial.

O lançamento desse livro marcou a própria inauguração da editora Noir sur Blanc, que se propunha a divulgar as literaturas polonesa e russa na Europa Ocidental (o Muro de Berlim ainda não caíra). Os quatro livros lançados no mesmo ano de 1987 foram: a coletânea de novelas russas Contes de la vie de tous les jours. Nouvelles satiriques soviétiques des années 1920, de Mikhaïl Zochtchenko (tradução de Michel Davidenkoff); o romance, também satírico e também russo, Le Bal des Bouffons, de Alexandre Shargorodsky (tradução de Maya Minoustchine), ambos na rubrica "literatura estrangeira"; e dois ensaios de Joseph Czapski: Proust contre la déchéance: Conférence au camp de Griazowietz e Souvenirs de Starobielsk, na rubrica "ensaios-documentos".

O parco impacto desses dois ensaios no mercado editorial pode ser devido à estrutura incipiente da editora (que, com o tempo, só fez expandir; hoje, a Noir sur Blanc faz parte do Grupo Libella, que reúne várias editoras). Mas, por que a publicação da obra de Joseph Czapski coube a uma editora suíça, se ele vivia nos arredores de Paris, anunciava um de seus textos como uma homenagem à literatura francesa, e tinha tantos contatos entre artistas e literatos no seu país de adoção?

Segundo informações do crítico Guillaume Gros, Czapski, é uma "figura da emigração polonesa nacionalista e cosmopolita" $^{20}$ e que, por isso, não era uma pessoa bem-quista pela intelectualidade de esquerda, que simpatizava com o regime soviético e prevalecia na mídia. Ora, essa definição ("figura da emigração polonesa nacionalista e cosmopolita") é, em si, um contrassenso (nacionalista $e$ cosmopolita?) e não corresponde à aspiração, proclamada pelo próprio Czapski (em entrevista veiculada no documentário de Andrzej Wolski, 2015; Cf nota n7), de ser "não nacionalista". A confusão entre anticomunista (ou antissoviético) e nacionalista (postura considerada, na França, como reacionária e retrógrada) vai estigmatizar o autor e sua obra, marcar (negativamente) sua trajetória, limitar seu espectro de interlocutores e, objetivamente, fechar-lhe muitas portas de editoras.

De um ponto de vista conceitual, a trajetória dos percalços do escritor e de seus livros - esse e os demais, mencionados a seguir - exemplifica o que o teórico André Lefevere define (com ênfase na perspectiva dos estudos da tradução, mas aplicada à literatura em geral) como "manipulação da literatura" ou controle do sistema literário, processo pelo qual se eliminam ou adaptam obras que firam ou se contraponham seja à poética (a

\footnotetext{
${ }^{18}$ CZAPSKI, J. op.cit, p.7.

${ }^{19}$ HERCHT, E. “Vingt-cinq ans d'éditions Noir sur Blanc”, L'Express, 21/09/2012, s/p; tradução livre.

${ }^{20}$ GROS, G. "Philippe Ariès sous le regard de Joseph Czapski et de Pierre Vidal-Naquet pendant la guerre d'Algérie", Histoire@Politique, 2013/2,n²0,p.135.
} 
concepção de literatura) seja à ideologia de uma sociedade. ${ }^{21}$ Nisso consiste a "patronagem": "poderes (pessoas, instituições) que auxiliam ou impedem a escrita, a leitura e a reescrita da literatura" ${ }^{22}$ No caso específico de Czapski, a patronagem atuou no sentido de cercear, se não censurar ostensivamente, a penetração de seus textos, contrários ao regime soviético. É o que se constata a seguir.

No imediato pós-guerra, Czapski publica títulos - entre livros, artigos e panfletos - em francês (seja diretamente ou traduzidos do polonês) que, como Proust contre la déchéance, transitam entre a memória, o ensaio e o testemunho histórico. Em ordem cronológica de publicação, tem-se:

1) em 1944, Lettre ouverte à Jacques Maritain et François Mauriac, [05/10/1944] (15 páginas grampeadas). Texto escrito diretamente em francês (único além de Proust contre la déchéance), que reproduz mensagens radiofônicas transmitidas durante o cerco de Varsóvia, em plena guerra, instando a intelectualidade francesa, através das figuras de Maritain e Mauriac, a tomar consciência da iminência do massacre. ${ }^{23} \mathrm{O}$ texto foi pouco difundido, inclusive por seu momento histórico e suas condições de produção;

2) em 1945, Souvenirs de staro: Bielsk (tradutor não mencionado). Paris: Éditions Témoignages, Cahier 1, 1945, "sob os auspícios do Exército Polonês”, coleção sob a direção do próprio Czapski; ${ }^{24}$ reedição com o título Souvenirs de Starobielsk, Lausanne: Éd. Noir sur Blanc, 1987 (prefácio de Gustaw Herling-Grudzinski ${ }^{25}$ ) e, em edição aumentada, em 2011. O crítico Christophe Pradeau explica que esse panfleto, publicado nos meses finais da guerra, deveria inaugurar a "Collection Témoignages", que seria dirigida por Czapski que, nesse momento, ocupa o posto de Chefe da Seção de Propaganda e Informação do Estado Maior polonês ${ }^{26}$ (essa edição é acompanhada de um prospecto que explica os princípios e o programa da coleção; o prospecto não será reproduzido na reedição; não há outras informações disponíveis sobre essa coleção nem sobre essa direção de Czapski).

3) em 1948, "Enfin la vérité sur Katyn", Gavroche (jornal cultural socialista francês), 12/05/1948, s/p;

4) em 1949, Terre Inhumaine ${ }^{27}$ (prefácio de Daniel Halévy, tradução de Maria-Adela Bohomolec), Paris: Editions Self, Librairie Plon; reedições (com o mesmo prefácio): Lausanne, Éd. L'Âge d'Homme, 1978 e 1991; e Paris: Noir sur Blanc, 2019; e

5) em 1950, "Pour les jeunes évadés de l'Est", Liberté de l'esprit, $\mathrm{n}^{\circ} 15,{ }^{28}$ (s/p). Essa revista mensal dirigida por Claude Mauriac, ${ }^{29}$ existiu entre 1949 e 1953, e tratava de arte, literatura, história e política. Tutelada por André Malraux e veículo privilegiado de Raymond Aaron, promove uma campanha de esclarecimento sobre o

\footnotetext{
${ }^{21}$ LEVEVERE, A. "Why waste our time on rewrites? The trouble of interpretation and the role of rewriting in an alternative paradigm. In: HERMANS, T. (Ed.) The manipulation of literature: Studies in literary translation. Londres: Croom Helm, 1985, p.215-243, p.226.

22 LEVEVERE, A, op. cit, p. 227.

${ }^{23}$ PRADEAU, C, "L'arche et le camp. Proust et Czapski”, Fabula / Les colloques, Proust: dialogues critiques, 2013, s/p.

${ }^{24}$ Esse texto escrito em polonês foi publicado primeiramente em 1944 pelo Instituto Literário da Polônia de Roma; também é em Roma que a revista Kultura, do mesmo instituto, é lançada.

25 (1919-2000), ensaísta, crítico literário e jornalista polonês, escreveu suas memórias de cárcere num gulag, publicado em Londres, em 1951. É um dos fundadores da revista Kultura, com Czapski.

${ }^{26}$ PRADEAU, C, op.cit, s/p.

${ }^{27}$ Livro publicado primeiramente em polonês, no mesmo ano, pelo Instituto Literário Polonês de Paris.

${ }^{28}$ Alguns críticos, em suas referências a essa publicação, anotaram, erroneamente, que se trata do ${ }^{\circ} 16$.

${ }^{29}$ (1914-1996), filho de François Mauriac e autor, entre outros, de Proust par lui-même (1953) e Malraux ou le mal du héros (1946) - menções que visam apenas reforçar a rede de nomes que se reencontram recorrentemente nesse contexto (André Malraux vai apoiar Czapski, como se vê logo adiante no texto).
} 
totalitarismo soviético durante a Guerra Fria; ${ }^{30}$ como seu diretor, a revista alinha-se a uma esquerda gaullista anticomunista, característica da IV República francesa (1946-1958).

Proust contre la déchéance é o único ensaio que não será editado no imediato pós-guerra. E Czapski deixa de escrever durante muito tempo, só voltando a publicar artigos e ensaios - sobre arte - a partir dos anos 1960. Uma explicação para isso talvez seja o fato de que ele volta a pintar no início dos anos 1950 (depois da interrupção forçada pelo conflito armado e suas sequelas), priorizando a pintura sobre a escritura. De qualquer forma, parece que dá sua tarefa de testemunho histórico por encerrada, ou desiste dela, considerando a pouca receptividade no mercado editorial como um todo (a primeira reedição de um de seus ensaios levou três décadas para ocorrer), e, particularmente, no mercado francês. Vejamos o caso de seu título mais divulgado: Terre inhumaine (1949, 1978, 1991 e 2019 - por três editoras diferentes, e o primeiro a ser reeditado) - e talvez o mais claro exemplo de patronagem.

Esse ensaio, que relata sua inquirição e denúncias do massacre de Katyn, teve o apoio, na França, de André Malraux (1901-1976) e de Raymond Aaron (1905-1983), que sugeriram sua publicação à editora CalmannLévy. Em entrevista incluída no documentário de Wolski, Czapski diz que, recebido por Calmann-Lévy graças à intervenção dos amigos, o editor lhe teria pedido que reduzisse as críticas à União Soviética (sem sucesso). O livro também foi apresentado à Gallimard, ${ }^{31}$ mas o escritor e jornalista Louis Aragon (1897-1982), comunista, pressionou a editora a postergar indefinidamente a publicação. Terre inhumaine será publicado em 1949 pela editora Self, conhecida por sua posição anticomunista (no mesmo depoimento incluído no documentário de Wolski, Czapski ri ao lembrar da editora Self, que chama de "reacionária" - o que indica que ele não se alinha a esse grupo).

As afinidades político-ideológicas de Czapski no meio intelectual e artístico francês se esboçam desde os tempos de suas atividades no movimento kapista, quando se aproxima, por exemplo, do historiador e ensaísta Daniel Halévy (1872-1962), que se interessara pelos kapistas - esse grande amigo de juventude de Proust, que, dreyfusard de primeira hora (como Proust), promotor das Universidades Populares na virada no século, mais tarde editor da ousada e progressista coleção Cahiers Verts (Grasset), mas que, depois da II Guerra Mundial, alinha-se à direita, inclusive apoiando o movimento conservador e monarquista Action Française. Czapski também será amigo do escritor e acadêmico François Mauriac (1885-1970), outro intelectual que vai atacar o regime soviético durante a Guerra Fria. A publicação de Terre inhumaine é, justamente, segundo testemunho do autor em entrevista, ${ }^{32}$ possibilitada pela ajuda de Daniel Halévy (que prefacia o livro) e respaldada por François Mauriac na imprensa. ${ }^{33}$ Já o crítico Pierre Grémion afirma que o historiador e jornalista Philippe Ariès ${ }^{34}$ teria

\footnotetext{
${ }^{30}$ GREMION, P. "Revues et maisons d'édition dans la guerre froide", Journées Souvarine 2010, n43, 2010, p.51

${ }^{31}$ GROS, G, op. cit, p.136.

${ }^{32}$ WOLSKI, A. e CZAPSKI, J. Czapski. Témoin du siècle, 59 min, 2015.

${ }^{33}$ Que escreve a seu respeito, por exemplo, o artigo "Les morts sans noms", Le Figaro, 4 de abril de 1949, apud GROS, G, op.cit, p.136, n.11.

34 (1914-1984), historiador herdeiro da Escola dos Anais, é considerado como um pioneiro da História das Mentalidades. Quando jovem, escreveu para a revista Action Française - católica e monarquista.
} 
intermediado o contato entre Czapski e a editora Plon (que abarca a Self) ${ }^{35}$ - em desdobramentos não comentados pelo autor em sua entrevista. ${ }^{36}$

Seja lá como for, os esforços despendidos para editar Terre inhumaine são por si só indício da patronagem exercida contra suas publicações na França; além disso, revelam o firme propósito de testemunhar fatos, registrar dados, lembrar nomes, elencar atrocidades fazendo deste livro, como de Proust contra a Degradação, um "lugar de memória” privilegiado.

\section{3 - Do oral aos escritos: traduções, perdas e ressurgências}

A obra literária de Czapski como que cai no esquecimento e parece meramente marginal diante da valorização de sua obra pictórica (que será respeitada e premiada dentro de um circuito restrito). Depois de sua morte (1993), apenas dois livros lhe são dedicados em língua francesa: Joseph Czapski, un destin polonais, de Emmanuel Dufour-Kowalski (L’Âge d'Homme, 1997) e Portrait de Czapski, de Wojciech Karpinski (L'Âge d'Homme, $2003^{37}$ ), publicados pela mesma editora suíça. O primeiro livro tem o título de um filme franco-suíço homônimo, de 1990 (63min), também realizado por Dufour-Kowalski, e fala do massacre de Katyn e da obra pictural de Czapski. O segundo livro parece ter desencadeado um interesse internacional sobre o pintor e ensaísta, pois, a partir do ano seguinte à sua publicação, haverá várias traduções e algumas reedições em francês de Proust contre la déchéance. Eis a lista completa até 2020 (em ordem cronológica) dessas traduções e reedições:

CZAPSKI, Joseph. La morte indifferente. Proust nel gulag. Tradução de M.C. Ciccimarra. Nápoles: L’Ancora del Mediterraneo, 2004.

CZAPSKI, Joseph. Proust. Vorträge im Lager Grjasowez. Tradução de Barbara Heber-Schärer. Belim: Friedenauer Presse, 2006.

\footnotetext{
${ }^{35}$ GRÉMION, P, op.cit, p.60.

${ }^{36}$ Sem enveredar por detalhes da biografia de Czapski, vale mencionar um apoio pontual que recebeu em solo francês de outro polonês: o cineasta e diretor teatral Andrzej Wajda (1926-2016). Primeiro, Wajda filma um depoimento de Czapski, que será lançado em 1988, junto com outros quatro curta-metragens integrados ao filme Les Français vus par. Trata-se de documentário (de 76 min, Erato Films e Socpresse-Le Figaro), composto de 5 episódios exibidos na televisão (Antenne 2), por ocasião da celebração do bicentenário da Revolução Francesa. O Figaro convidara cinco diretores famosos a fazerem curta-metragens para celebrar, na mesma oportunidade, os dez anos de sua revista, tendo por tema "os franceses vistos por" estrangeiros. Wajda realiza "Proust contre la déchéance", que será o terceiro curta, uma entrevista com Czapski sobre sua sobrevivência no gulag "graças a Proust" (Anônimo, 1988, s/p; dos cinco curtas, é um dos dois que não se encontram disponíveis na internet) - evidentemente, intitulado em função do livro que acabara de ser lançado

Quase vinte anos depois, Wajda faz Katyn (2007), filme polonês sobre o massacre (no qual seu pai morrera), que recebe o Oscar de melhor filme estrangeiro em 2008, e passa em um circuito restrito de cinemas na França, em 2009. O DVD é lançado com um "bônus": a entrevista realizada com Czapski, que falara, em 1888, do massacre e de Proust.

Outro filme, que mencionamos antes, é de outro polonês radicado na França. Andrzej Wolski (1924-2011), que realizou mais de quarenta documentários para a televisão (sobretudo francesa), e fez a biografia de Czapski já citada, em 1985 (mesmo ano de seu documentário sobre o Instituto Literário Polonês de Paris, Culture Monthly; conselho artístico de Wajda) - reeditado por ARTE-Instituto do Filme Polonês em 2015 e disponível (temporariamente) na página web da emissora ARTE (ver bibliografia).

${ }^{37}$ Traduzido do polonês; livro que teve sua primeira versão em língua inglesa, em 1996.
} 
CZAPSKI, Joseph. Proust contre la déchéance. Conférences au camp de Griazowietz. Édition revue et augmentée. Lausanne: Éditions Noir sur Blanc, 2011.

CZAPSKI, Joseph. Proust contre la déchéance. Conférences au camp de Griazowietz. Paris: Libretto, 2012.

CZAPSKI, Józef. Proust contra la decadência. Tradução de Mauro Armiño. Madri: Siruela, 2012.

CZAPSKI, Józef. Proust a Grjazovec. Tradução de Barbara Delfino. Milão: Adelphi, 2015.

CZAPSKI, Jozef. Lost Time. Lectures on Proust in a Soviet Prison Camp. Introdução e tradução de Eric Karpeles. Nova York: New York Review Books, 2018.

CZAPSKI, Joseph. Proust contra a Degradação. Tradução de Luciana Persice Nogueira. Belo Horizonte-Veneza, Âyiné, 2018.

Primeiramente, vale repetir que das três das edições em francês (1987, 2011 e 2012), duas são suíças e a francesa é de uma editora do Grupo Libella, e, portanto, ligada à editora suíça - numa continuidade editorial; o último título traz a novidade do formato de bolso, que tem maior capacidade de popularização da obra. Talvez essa edição, nesse formato, seja mais diretamente responsável, em consequência da divulgação ampliada da obra, pelo interesse que provocou as quatro traduções subsequentes.

Também deve-se notar que a primeira tradução para outro idioma (que não o polonês - língua da primeira publicação traduzida, em dois números consecutivos da revista Kultura, dirigida pelo autor, em 1944) foi feita em italiano, em 2004, alterando o título ("a morte indiferente" - que é uma citação de Proust, que Czapski comenta no meio e ao final de seu ensaio; também se faz menção a "gulag", evitando o nome do local, que talvez não seja suficientemente evocativo para o leitor); note-se igualmente que, em 2015, haverá uma segunda tradução para o italiano - de outra editora, com outro título (também ele diferente do escolhido pelo autor, mas igual à versão polonesa - em referência direta ao local do gulag) e com outra grafia para o nome do autor.

Essa é uma questão (ou um dilema) recorrente nas traduções - usar ou não o nome original do autor. No caso, a maioria das editoras manteve a grafia afrancesada (transliterada) "Joseph". Além da segunda tradução italiana, somente a espanhola e a norte-americana optaram por "Józef".

Com relação à tradução para o inglês, cabe ressaltar alguns elementos que destacam essa edição das demais, pois o tradutor não se limita à transposição de uma língua a outra: realiza uma pesquisa apurada, inclusive in loco, faz entrevistas, escreve artigos, tornando-se particularmente "visível" enquanto tradutor-comentarista, intervindo na recepção da obra em seu país. ${ }^{38}$

O pintor norte-americano Eric Karpeles (1953), é também tradutor, ${ }^{39}$ escritor, ${ }^{40}$ e crítico de arte. Sua obra escritural - como tradutor e escritor, onde predomina a análise do trabalho de Proust - lhe dava bagagem

\footnotetext{
${ }^{38}$ Karpeles coloca em prática ditames de Lawrence Venuti em seu The Translator's Invisibility: A History of Translation. Londres e Nova York: Routledge, 1995. Um aprofundamento dessa questão, porém, não cabe na economia desse artigo.

${ }^{39}$ Traduziu Proust's overcoat: The True Story of One Man's Passion for All Things Proust (2010), de Lorenza Foschini (Il cappotto di Proust. Storia di un'ossessione letteraria, 2008).

${ }^{40}$ Entre outras produções textuais, escreveu o prefácio da tradução de On Reading, de Marcel Proust (2011); o ensaio Paintings in Proust: A Visual Companion to In Search of Lost Time (2008; tradução para o francês de Pierre Saint-Jean: Le Musée imaginaire de Marcel Proust: Tous les tableaux de A la recherche du temps perdu, 2009 e 2017); e o que ele denomina uma trilogia sobre Czapski: Lost Time. Lectures on Proust in a Soviet Prison Camp (a tradução prefaciada, 2018), Almost Nothing, a critical biography (2018, uma biografia crítica; mais uma vez, a editora Noir Sur Blanc entra em cena, e traduz esse livro para o polonês, em 2019), e An Apprenticeship of Looking, an artist's monograph (2019, um ensaio sobre arte pictural de Czapski).
} 
avalizada para também fazer a introdução do livro; ele vai à França para poder conhecer a obra pictórica de Czapski - premiada mas pouco divulgada - e visita a sede do Instituto Literário Polonês em Paris (onde aliás Czapski residiu durante toda a sua vida no exílio), entrevistou conhecidos do escritor polonês e consultou material de difícil acesso. Talvez o seu olhar estrangeiro à situação daquele dito "imigrante polonês nacionalista cosmopolita", que teve tantas dificuldades para encontrar espaço e trégua para divulgar sua obra na França tenha-lhe permitido falar, em seus ensaios, sobre a homossexualidade de Czapski, sua amizade com Daniel Halévy (amigo íntimo de Proust e fonte prodigiosa de informações e anedotas de que Czapski pode ter se lembrado sem dificuldade em suas conferências, animando-as com as cores vivas da Belle Époque); esses dados biográficos ajudam o tradutor a inferir conclusões, como por exemplo o fato de que Czapski lê - e finalmente aprecia - Proust ao convalescer de uma doença e de um amor frustrado, fato que o ajudaria a compreender melhor as amofinações amorosas do narrador.

Karpeles também valoriza a amizade entre Czapski e outros amigos de Proust, como o poeta e ensaísta LéonPaul Fargue (1876-1947) e a pianista Misia (Maria) Godebska-Sert (1872-1950, viúva de Thadée Nathanson, um dos donos da famosa Revue Blanche, onde Proust, Halévy e outros amigos publicaram escritos da juventude); junto com Picasso, Misia organiza o baile que ajuda Czapski a arrecadar fundos para os artistas kapistas (evento mencionado anteriormente). Essa "história oral", de fato, pode ser uma das fontes não literárias que ajudaram Czapski a rechear suas palestras e distrair seu auditório. Outra fonte de conhecimentos de Czapski revelada por Karpeles em seus ensaios é o próprio estudo de crítica literária publicado por Czapski na Polônia, em janeiro de 1928, poucos meses depois da publicação do último volume da Recherche (na França), constituindo, segundo o norte-americano, uma das primeiras resenhas feitas sobre a totalidade da Recherche. ${ }^{4142}$ De fato, é possível lembrar-se com mais nitidez de algo sobre o qual se escreveu, e dar-lhe prosseguimento e expansão em desenvolvimentos e especulações orais.

A introdução de Karpeles (que apresenta sua tradução) - publicada em separado na revista eletrônica Literary $\mathrm{Hub}^{43}$ - explica também a situação da Polônia na década de 1930, e os eventos que Czapski deve enfrentar ao se preparar para a guerra, assim como dá detalhes sobre os diversos gulags e seus contingentes quando da deportação e prisão de Czapski. Karpeles, finalmente, analisa o processo de rememoração de Czapski, comparando-o ao de Proust (superficialmente, pois não se trata de uma tese). Fato, talvez, mais importante, o tradutor usa e compara duas versões datilografadas, "originais", e nas discrepâncias entre as versões (raras, segundo ele) opta por aquela em que a narrativa é valorizada. Ele não explica, porém, essa existência de dois tapuscritos.

O texto publicado pela Noir sur Blanc em 2011, usado pela maioria das traduções do livro (inclusive a brasileira), não faz menção a essa duplicidade de tapuscritos. Aliás, a publicação de 2011 simplesmente suprime,

\footnotetext{
${ }^{41}$ KARPELES, E. “The Question of What Is True: Eric Karpeles on Józef Czapski” (entrevista de Mikolaj Glinski), 9/05/2019. Literaty Hub. https://culture.pl/en/article/the-question-of-what-is-true-eric-karpeles-on-jozef-czapski, s/p.

42 "Marceli Proust", Przeglqd Wspótczesny ("Horizonte contemporâneo"), v.XXIV, n71, 1928, p.494-517, reeditado noutra revista polonesa em 1983 (Patrzqc, Cracóvia, p.9-29), apud MAINBERGER, S. e STEWART, N, op. cit, 2016, p.58, n.2. Sabine Mainberger também se refere, com mais detalhes, a esse artigo (seu trabalho é comentado a seguir).

43 KARPELES, E. "The Polish Army Officer Who Conjured Proust in a Soviet Prison Camp. On Józef Czapski's Wartime Lectures", 07/11/2018, <https://lithub.com/the-polish-army-officer-who-conjured-proust-in-a-soviet-prison-camp/>, acesso em 03/05/2020, s/p.
} 
na nota introdutória dos editores, a informação (que consta na edição de 1987) de que o primeiro manuscrito, ditado ainda no campo soviético, se perdeu, e que o texto publicado é, portanto, resultando de um segundo ditado, feito entre 1943 e 1944. Essa duplicidade de ditados, de versões e de tapuscritos reverbera toda a complexidade da passagem do oral ao escrito, desde a conferência proferida no gulag siberiano até a sua primeira publicação na Suíça, quarenta e cinco anos depois, que constitui, em si, verdadeira saga de sobrevivência entre perdas, resgates, versões e traduções.

Essas são duas questões de monta que despontam em meio à pletora de informações aqui recolhidas para uma melhor compreensão da saga da obra de Czapski: a duplicidade dos tapuscritos e a passagem do oral ao escrito. Comecemos pela segunda.

A trajetória claudicante da obra pode ser retraçada com a ajuda de um estudo, que delineia percursos e percalços do material relativo às conferências de Czapski. Dois pesquisadores de universidades alemãs, Sabine Mainberger e Neil Stewart, organizaram À la recherche de la Recherche. Les notes de Joseph Czapski sur Proust au camp de Griazowietz, 1940-1941 (2016, edição bilíngue francês-alemão), que reúne quatro ensaios ${ }^{44}$ - sempre pela Noir sur Blanc (a filial parisiense do grupo). Na Introdução do livro, S. Mainberger reitera que, ainda no gulag, Czapski ditara seu ensaio a dois companheiros de prisão (aos quais rende homenagem, nomeando-os na introdução, escrita em 1944, do ensaio: "W. Tichy e Imek Kohn"). ${ }^{45}$ A pesquisadora acrescenta, porém, que na versão polonesa, de 1948, o autor volta a homenageá-los, dedicando-lhes a obra: "J. (Joachim) Kohn" e "W. (Wladyslaw) Cichy (Tichy)”; ${ }^{46}$ os nomes, porém, aparecem diferentes; ela não explica, no entanto, essa diferença. De qualquer forma, a hipótese mais provável é de que eles se revezassem na escrita de um único manuscrito (havia pouco papel à disposição dos detentos). Esse manuscrito, no momento de anistia e reintegração à ativa, se perdeu. Mesmo assim, sabe-se que foi redigido em francês, pois o autor revela, no prefácio à tradução publicada na revista Kultura, que "as conferências ocorreram dentro do contexto de aulas de conversação francesa”, ministradas por ele a um grupo de uns quarenta audientes. ${ }^{47}$ À mesma ocasião, desaparece, também, parte dos cadernos de anotações de Czapski (recheados de textos curtos e diagramas).

Perde-se, assim, o texto escrito, de fato, como anunciado na apresentação do texto publicado, "no calor do momento": expressão usada pelos editores suíços e reproduzida nas traduções da obra (como já dito). Pode-se apenas especular sobre esse manuscrito desaparecido, ditado pelo autor a dois amigos, também poloneses francófonos, que devia preservar elementos da oralidade tanto do discurso ditado quanto da reprodução do formato das conferências, num hibridismo redobrado entre fala e escrita. A própria circunstância da repetição do conteúdo aos amigos-anotadores, que também foram audientes das conferências, amplia essa oralidade a uma eventual coparticipação dos amigos, que podem ter ajudado a rememorar (discutindo, questionando etc) as palestras no momento do ditado.

\footnotetext{
${ }^{44}$ Além da Introdução de Sabine Mainberger, há o seu artigo "Graphismes et mémoire”, também: "Pages des cahiers de Griazowietz", de Neil Stewart, "Petite histoire de la réception de Proust en Pologne”, de Mieczylaw Dabrowski, e "Le charme, le charme de Proust. Extraits du Journal, 1942-1989”, de Janusz S. Nowak.

${ }^{45}$ O autor explica, na introdução, escrita em 1944, que o primeiro é "redator da versão polonesa de Parade, no Cairo”; o segundo, médico militar (CZAPSKI, J, op.cit, p.12).

${ }^{46}$ MAINBERger, S. e STEWART, N, op.cit, p.22.

${ }^{47}$ MAINBERGER, S. e STEWART, N, op. cit, p.23ss; tradução livre.
} 
Quanto à questão da duplicidade dos tapuscritos, novamente o ensaio de Mainberger é esclarecedor: nele se explica que entre 1943 e 1944, postado no Irã, o autor volta a ditar seu ensaio, que será datilografado por duas pessoas diferentes - em duas versões ligeiramente distintas. A pesquisadora alerta para o fato de que essa reconstituição datilografada das conferências, em dois exemplares, não configura um conjunto de original e cópia carbono, mas de duas versões batidas à máquina concomitantemente, por dois datilógrafos. Isso se infere por diferenças na formatação e disposição do texto na página e na numeração das páginas, por exemplo, e porque cometem "erros diferentes", ${ }^{48}$ entre outros indícios - em, portanto, um segundo registro de ditado feito por Czapski a duas pessoas (estas, não identificadas). Em dezembro de 1943, a parte final do ensaio é publicada no jornal La Marseillaise com o título "Orientation de l'oeuvre de Proust, par le capitaine Czapski” (não foi dito a partir de qual versão). O texto publicado pela Noir sur Blanc em 1987 corresponde à versão datilografada n¹, completada e/ou corrigida pela versão $n^{\circ} 2$ (fato não explicitado pela editora) - não sendo, então, o texto resultante do primeiro ditado, feito no "calor do momento" e no frio do inverno da Sibéria - como anunciado pelos editores.

A saga das perdas tem novo capítulo. Em 1987, os cadernos que permaneceram em posse de Czapski foram cedidos temporariamente à editora para a reprodução de alguns dos diagramas, e foram devidamente devolvidos. Desde a morte do autor, porém, estavam sob a guarda de um sobrinho do artista (Janusz Przewlocki), mas, depois do falecimento deste, em 2010, os cadernos não foram encontrados. Estão, também eles, portanto, destruídos, desaparecidos ou extraviados. Assim, perderam-se todos os documentos originais - o texto manuscrito ditado no gulag e o conjunto dos cadernos de notas e diagramas (estes, em duas etapas: 1941 e [2010?]; acrescentem-se a essas perdas, as dos diários que o escritor redigiu entre 1917 e 1939, assim como toda a sua obra pictórica antes da II Guerra Mundial) num deplorável roldão de sumiços e descaminhos da produção artística de Czapski.

Restam, assim, os textos datilografados, ${ }^{49}$ que deram origem ao ensaio publicado em 1987. Isso, no entanto, não desmerece em nada seu valor de registro histórico das conferências, nem de documento enquanto objeto da crítica genética. $\mathrm{O}$ autor, aliás, talvez na tentativa de recuperar a contemporaneidade perdida, encarregou-se de manter a vivacidade de um testemunho de primeira mão simulando a concomitância entre o oral e o escrito, usando, no livro, elementos de oralidade que levam o leitor a imergir no contexto das conferências (repetindo, com alguma insistência, por exemplo, expressões como "Eu já lhes falei" ${ }^{\text {”0 }}$ ).

De uma perspectiva geneticista, quanto ao texto matricial original, o leitor de hoje conhece, além dessa "segunda versão original" finalmente publicada, algumas reproduções dos diagramas escritos e desenhados por Czapski - presentes na capa e no interior do livro (inclusive de traduções). São o que resta de autêntico da vivência do gulag e das conferências lá realizadas. Por isso, constituem o principal objeto de interesse de Sabine Mainberger.

\footnotetext{
${ }^{48}$ MAINBERGER, S. e STEWART, N, op, cit, p.20ss.

${ }^{49}$ Em princípio, esses documentos estão no Museu Emeryk Hutten-Czapski (que leva o nome do avô do escritor, grande colecionador de livros e moedas), na Cracóvia, juntamente com os diários do artista, anotações diversas, além de alguns de seus desenhos, esboços e croquis.

${ }^{50}$ CZAPSKI, J, op.cit, p.23, entre outras. A questão da oralidade no texto, tal como foi traduzido, assim como aspectos da própria tradução para o português, são objeto de outro artigo.
} 
Em seu capítulo "Grafismos e memória”, a pesquisadora ressalta um elemento de difícil percepção a partir das reproduções nos livros: "as notações são feitas em várias etapas". ${ }^{51}$ Tendo tido acesso direto a esse material, ela esclarece (em descrição detalhada) que, primeiro, o autor faz notas a lápis - em sua maioria, elas são escritas em polonês, mas há também palavras ou trechos em francês e em russo; em seguida, escreve por cima com tinta da china e maiúsculas. Então, acrescenta, em preto, elementos gráficos (contornos, sublinhados etc); em seguida, reproduz o mesmo tipo de grafismo usando diferentes cores. Depois dessas camadas de escritura e elementos gráficos, o autor acrescenta frases em letra cursiva, no espaço disponível. Finalmente, flechas e traços conectam fragmentos de texto em diferentes partes da folha.

Essas diferentes etapas e camadas de anotações e desenhos materializam distintos momentos da reflexão do autor, e se acumulam ao grado de seus raciocínio e lembranças. Mapas mentais (sob uma perspectiva didática), são conjuntos orgânicos de marcas e marcações visuais que indicam associações e composições a serem feitas na exposição oral, às vezes acompanhadas de algarismos, que devem servir para estabelecer a ordem na qual sequenciar a explanação; num segundo momento, essas imagens também atendem à necessidade de ditar a conferência aos amigos, como um aide mémoire à transcrição; num terceiro momento, novamente, servem de esquema mnemônico para o ditado aos datilógrafos. A dupla função de plano de narração e roteiro de narrativa reverbera outras duplicidades, além de oralidade e escrita: texto e desenho, ensaio e arte.

Esses hibridismos permitem ao leitor, por meio dessas folhas ilustradas, inseridas entre as páginas do ensaio, mergulhar numa mise en abyme metaescritural que embaralha distintos tempos da produção do texto, superpostos no resultado "acabado", publicado, mas "abertos" ao descobrimento e decodificação. O livro assim composto, com as páginas de texto recheadas de (parte de) seu antetexto ${ }^{52}$ iconográfico e metaescritural, permite ao leitor de hoje o exercício lúdico e exploratório de tentar retraçar, comparando (se assim o desejar) texto final e imagens matriciais, atestando o valor heurístico do conjunto dos documentos do processo criativo.

\section{Concluindo: arqueologia de uma vontade de memória}

Czapski, espécie de Sherazade circunstancialmente siberiana, conta histórias para não morrer, desfia palestras para distrair mentes, consolar espíritos, relembrar tempos melhores. Proust, sua obra e seu mundo narrado são usados pelo conferencista polonês como arma contra a degradação dos seres e o esquecimento das coisas belas. Ao escrever Proust contre la déchéance, sobre essa vivência pessoal e histórica, o escritor encena um longo e atribulado percurso: dos diagramas que prepararam às aulas e subsidiaram o ditado do texto, à perda do primeiro manuscrito e de cadernos anotados durante o confinamento, ao segundo ditado, à duplicidade dos tapuscritos, às recusas de publicação (deste e de outros títulos), à versão em polonês, ao amálgama dos tapuscritos publicado por uma editora suíça 43 anos depois do primeiro ditado, que resulta numa recepção pífia junto ao público francês. Mais 25 anos se passam para que haja uma segunda publicação, esta produzida no bojo de um movimento internacional de interesse por Proust contre la déchéance, desencadeado por livros e filmes realizados por artistas poloneses, conhecidos ou amigos do escritor, em seguida à sua morte.

\footnotetext{
${ }^{51}$ MAINBERGER, S. e STEWART, N, op.cit, p.51ss.

52 Termo cunhado por Jean Bellemin-Noël num dos textos fundadores da crítica genética, Le Texte et l'avant-texte: Les brouillons d'un poème de Milosz. Paris: Larousse, 1972.
} 
Proust contra a Degradação é um ensaio curto, mas o estudo de sua gênese, de seus infortúnios e do processo de sua redenção junto ao público leitor dariam uma tese substanciosa, não isenta de polêmica. Tanto as agruras da publicação quanto o insucesso de sua primeira edição parecem se dever às contingências da patronagem (Levefere); os descaminhos do livro, porém, revelam, além das dificuldades contextuais, a vontade férrea do autor de registrar seu testemunho. Livro que se torna, assim, lugar de memória (Nora) que, para além de seu valor intrínseco de crítica de arte, arquiva dados, fatos, nomes, gestos, rastros de um momento histórico que, se não fosse pelo produto escrito, e reescrito, por Czapski e seus anotadores, se perderia. Tempo, portanto, recuperado pela arte e pela vontade desse polonês obstinado.

Proust contra a Degradação é um ensaio parcialmente ilustrado (em maior ou menor medida, de acordo com a edição), que permite ao leitor um mergulho múltiplo. Da mise en abyme de projetos de escritura, de situações de confinamento e de buscas de redenção pela arte (entre Czpski e Proust), à mise en abyme entre texto e antetexto, numa possível dupla leitura.

Os diagramas representam a ocupação quase integral do espaço da página no esforço do ordenamento das ideias e das lembranças, da sequência do discurso a ser proferido nas aulas, da distribuição do tempo do relato. São um apelo visual e sintético de tudo que há a ser recuperado, retraçado, recomposto na fala sobre Proust, sua obra e seu tempo. Verdadeira materialização da transposição das artes, do pictórico ao escritural, o diagrama (que inclusive possui conteúdos que não são desenvolvidos no ensaio), em nova duplicidade, desdobra a transposição entre línguas, fronteiras, culturas e escritores - Czapski e Proust.

\section{Referências}

ANôNIMO. "Józef Czapski. Biographie", Kultura Paryska, s/d. Disponível em: <http://kulturaparyska.com/fr/ludzie/pokaz/c/jozef_czapski>. Acesso em 29 abr 2020.

ANONIMO. "LES FRANÇAIS VUS PAR... Un grand magazine du cinéma d'auteur", Le Monde, 23/10/1988.

Disponível em: <https://www.lemonde.fr/archives/article/1988/10/23/les-francais-vus-par-un-grandmagazine-du-cinema-d-auteur_4119946_1819218.html>. Acesso em 02 mai 2020.

BELLEMIN-NOËL, Jean. Le Texte et l'avant-texte: Les brouillons d'un poème de Milosz. Paris: Larousse, 1972.

BRETON, André. Manifestes du surréalisme. Paris: Gallimard, 1972.

CZAPSKI, Joseph. Proust contra a Degradação. Tradução de Luciana Persice Nogueira. Belo Horizonte-Veneza: Âyiné, 2018.

CZAPSKI, Joseph. Proust contre la déchéance. Lausanne: Noir sur Blanc, 1987 e 2011.

GREMION, Pierre. "Revues et maisons d'édition dans la guerre froide". Journées Souvarine 2010, n43, 2010, p.47-62.

GROS, Guillaume, "Philippe Ariès sous le regard de Joseph Czapski et de Pierre Vidal-Naquet pendant la guerre d'Algérie”, Histoire@Politique, 2013/2, n²0, p. 134-154. DOI: 10.3917/hp.020.0134. Disponível em: < https://www.cairn.info/revue-histoire-politique-2013-2-page-134.htm>. Acesso em 28 abr 2020. 
GUERIN, Jeanyves. "La gauche progressiste et l'analyseur Proust", Travaux et Recherches de l'UMLV, Université de Marne-La-Vallée, 2004, p.169-184. Disponível em: <https://hal-univ-paris3.archives-ouvertes.fr/hal01446939/document>. Acesso em 02 jun 2021.

HECHT, Emmanuel. "Vingt-cinq ans d'éditions Noir sur Blanc", L'Express, 21/09/2012. Disponível em <https://www.lexpress.fr/culture/livre/vingt-cinq-ans-d-editions-noir-sur-blanc_1163673.html>. Acesso em 28 abr 2020.

<http://www.ladilettantelle.com/article-proust-au-goulag-une-histoire-envoutante-66509124.html>. Acesso em 18 dez 2020.

KARPELES, Eric. "The Polish Army Officer Who Conjured Proust in a Soviet Prison Camp. On Józef Czapski's Wartime Lectures", 07/11/2018. Disponível em:

$<$ https://lithub.com/the-polish-army-officer-who-conjured-proust-in-a-soviet-prison-camp/>. Acesso em 03 mai 2020.

KARPELES, Eric. "The Question of What Is True: Eric Karpeles on Józef Czapski” (entrevista de Mikolaj Glinski), 9/05/2019. Literaty Hub. Disponível em: <https://culture.pl/en/article/the-question-of-what-is-true-erickarpeles-on-jozef-czapski>. Acesso em 01 mai 2020.

LEFEVERE, André. "Why waste our time on rewrites? The trouble of interpretation and the role of rewriting in an alternative paradigm. In: HERMANS, T. (Ed.) The manipulation of literature: Studies in literary translation. Londres: Croom Helm, 1985, p.215-243.

MAINBERGER, Sabine e STEWART, Neil (Dir.). À la recherche de la Recherche. Les notes de Joseph Czapski sur Proust au camp de Griazowietz, 1940-1941. Paris: Noir sur Blanc, 2016.

NORA, Pierre. Entre história e memória: a problemática dos lugares (Tradução de Yara Aun Khoury), Revista Projeto História, v. 10, p.7-28, 1993.

PRADEAU, Christophe, "L'arche et le camp. Proust et Czapski", Fabula / Les colloques, Proust: dialogues critiques, 2013. Disponível em : <http://www.fabula.org/colloques/document2164.php>. Acesso em 01 mai 2020. VENUTI, Lawrence. The Translator's Invisibility: A History of Translation. Londres e Nova York: Routledge, 1995. WOLSKI, Andrzej e CZAPSKI, Joseph. Czapski. Témoin du siècle, $59 \mathrm{~min}, 2015$. Disponível em: <https://www.arte.tv/fr/videos/054728-000-A/jozef-czapski-1896-1993/>. Acesso em 13 mai 2020.

Recebido em: 12 de janeiro de 2021 Aceito em: 08 de junho de 2021 